\title{
Monoclonal Antibody CEM-231
}

National Cancer Institute

\section{Source}

National Cancer Institute. Monoclonal Antibody CEM-231. NCI Thesaurus. Code C29217.

A monoclonal antibody directed ag ainst carcinoembryonic antigen (CEA) which is

expressed by most gastrointestinal carcinomas and by some breast, lung and ovarian carcinomas. ( $\mathrm{NCl04)}$ 